\title{
OUTRO OLHAR SOBRE A HUMANIDADE NEGRA: ENTREVISTA COM \\ HELOISA PIRES LIMA
}

\section{ANOTHER LOOK AT BLACK HUMANITY: INTERVIEW WITH HELOISA PIRES LIMA}

Esdras Soares da Silva ${ }^{1}$

Resumo: Entrevista com a escritora, antropóloga, editora e educadora Heloisa Pires Lima.

Abstract: Interview with writer, anthropologist, editor and educator Heloisa Pires Lima.

Palavras-chave: Literatura para crianças e jovens; Literatura afro-brasileira; Representações culturais.

Keywords: Literature for children and young; Afro-Brazilian literature; Cultural representations.

Heloisa Pires Lima é escritora, antropóloga, editora e educadora. Nascida em Porto Alegre, ainda na infância se mudou para São Paulo. Cursou graduação em Psicologia na Pontifícia Universidade Católica de São Paulo (PUC-SP) e Ciências Sociais na Universidade de São Paulo (USP). Também foi nesta universidade que cursou mestrado e doutorado em Antropologia Social, com foco nas representações culturais.

Sua obra mais conhecida é Histórias da Preta, publicado em 1998 pela editora Companhia das Letrinhas (com ilustrações de Laurabeatriz). A obra recebeu os prêmios José Cabassa e Adolfo Aizen da União Brasileira dos Escritores (UBE), o selo “Altamente Recomendável” da Fundação Nacional do Livro Infanto Juvenil (FNLIJ) e foi selecionado para o Brazilian Book Magazine divulgado na Bologna Book Fair. Além disso, é autora de diversos outros títulos para crianças e jovens, como Quilombololando (ilustrações de Joaquim de Almeida, 2016, Amarilys); O coração do baobá (ilustrações de Laerte Silvino, 2014, Amarilys); O pescador de histórias (ilustrações de Élon Brasil, 2013, Melhoramentos); O fio d'água do quilombo: uma narrativa do Zambeze no Amazonas?,

1 Mestrando do Programa de Pós-Graduação em Estudos Comparados de Literaturas de Língua Portuguesa da Universidade de São Paulo (USP). 
em coautoria com Willivane Ferreira de Melo e Águida Maria Araújo de Vasconcelos (Prumo, 2012); Toques do griô, em coautoria com Leila Leite Hernandez (ilustrações de Kaneaki Tada, 2011, Melhoramentos); O marimbondo do quilombo (ilustrações de Rubem Filho, 2010, Amarilys); Lendas da África Moderna, em coautoria com Rosa Maria Tavares Andrade (ilustrações de Denise Nascimento, 2010, Elementar); O comedor de nuvens (ilustrações de Suppa, 2009, Edições Paulinas); Benjamin, o filho da felicidade (ilustrações de Marcelo Pacheco, 2007, FTD); A semente que veio da África, em coautoria com Georges Gneka e Mário Lemos (ilustrações de Véronique Tadjo, 2005, Salamandra); e $O$ espelho dourado (ilustrações de Taisa Borges, 2003, Peirópolis). Também é uma das autoras do importante De olho na cultura: pontos de vista afro-brasileiros (2005).

$\mathrm{Na}$ entrevista a seguir, realizada por e-mail no dia 19 de junho de 2020, Heloisa fala sobre a relação de seu ofício de antropóloga com a escrita de seus livros, compartilha reflexões sobre obras de sua autoria e de coleções e títulos que foram publicados sob sua coordenação, faz considerações sobre a dimensão das ilustrações e destaca as múltiplas possibilidades que o texto literário oferece, inclusive na transformação do olhar sobre a humanidade negra.

Revista Crioula: Você é antropóloga, com foco nas representações culturais. Como esse ofício e sua trajetória se relacionam com a escrita de seus livros?

Heloisa Pires Lima: Vou começar, então, pela minha relação com os livros, desde o primeiro que eu tateei, senti o cheirinho da tinta e me maravilhei com os desenhos que abriam e fechavam a história. Mas, alguns tinham algo a mais para me contar. Um dia eu fiquei horas olhando a abóbora plantada por meu pai no quintal de casa, tentando descobrir como ela poderia virar uma carruagem como no conto que acabara de ler. Embora o enredo me engolisse, sempre havia uma realidade para colocá-lo à prova. Devo ter concluído que a imaginação sem fim pode, com ela, coexistir. Pois é assim, lá no meio do literário algum detalhe fascina e ensina. Na adolescência, Iracema, a América ao contrário de Alencar, foi uma descoberta êxtase sobre intenções projetadas para um projeto literário. Graciliano Ramos me escancarou o uso da linguagem seca me atirando para dentro da caatinga narrada, em grande estilo. E Machado desnudava minha alma e a exibia, sem pudor, em minúsculos parágrafos. Que magia era aquela? Logicamente, é como, hoje, percebo o impacto de algumas remotas leituras em mim. E poderia seguir por aquelas geracionais que dirigiram a minha e outras vidas ostentando o poder que embutiam. 
Mas, prefiro pontuar a pequena biblioteca da sala de aula quando estava educadora, atuando desde o berçário até a alfabetização. O momento, que dura até hoje, enlaçou minha paixão por literatura e infância. A antropologia ajustou o foco. De imediato, os acervos disponibilizados se mostraram aldeias que falam sobre a época e o circuito produtor das obras. A abordagem dos repertórios preserva um sistema de argumentos culturais, o que ficou mais explícito quando busquei a presença-ausência da origem continental africana na infinidade de possibilidades diaspóricas. Essa fonte inesgotável me levou ao meu doutoramento. A tese Negros debretianos: representações culturais presentes na obra Voyage pittoresque et historique au Brésil (1816 a 1839) investigou, na edição original, como os habitantes negros foram percebidos por Debret. Ou seja, mantive o repertório no vínculo específico e trabalhei, teoricamente, com o mote das representações culturais cujas bibliotecas mirins já me alertavam. Se bem delimitadas, as inúmeras correlações para análise trazem o circuito das publicações do período, tecnologias envolvidas, enredo interseccionado com o percurso da biografia institucional do autor, a disputa de narrativas sobre o Brasil. Tudo para desnublar como a autoria confeccionou e posicionou os habitantes negros naquele imaginário.

Por sua vez, desde 1997 eu participava pela Fundação Palmares das consultas do então deputado Paulo Paim, prévias para o projeto História da África, em debate na Câmara. Um dos pontos estava na inadequação da representação de África nos compêndios didáticos, extensivo aos paradidáticos. Minha contribuição vinha por produzir materiais. Um pouco antes, em 1995, eu coordenava a coleção Orgulho da Raça, voltada para a educação infantil, pela editora Memórias Futuras, do Rio de Janeiro. Sabendo dos problemas de representação e representatividade nas estantes, foi a chance para a atitude mais propositiva. Todos os títulos apresentavam as mais diversas chaves emocionais. Sônia Rosa trouxe $O$ Menino Nito, até hoje um clássico do personagem que "desachorava", combatendo, implicitamente, o machismo. Carlos Jorge com Favela, minha morada intencionava o positivo na referência. Solange Cianni apresentou uma princesa iorubá reproduzindo uma vivência na sala de aula. Uma aluna nigeriana, iorubá, que entrara na escola era muito agredida ora por ter o cabelo assim, ora porque falava "errado" por conta do sotaque. Então, a educadora foi criando na roda de histórias uma bela princesa com cabelos encaracolados, lábios carnudos e pele admirável como da menina real. E ao final, deu o nome Omolobakê, para a personagem igual ao da aluna. E ainda ensinou a sala a falar iorubá por conta de um bordão "eê karo!", "bom dia" nessa língua. Em uma semana a classe toda queria ser Omolobakê, assim informava a carta que acompanhou o texto endereçado à editora. A proposta aparentemente pueril realizava uma complexa inversão cultural. A literatura derretia, feito manteiga, percepções que causariam dor.

Em 1998 veio o Histórias da Preta pela Companhia das Letrinhas deslocando a referência feminina 
da periferia para o centro da capa. No caso, uma figura negra que não sofreu nem branqueamento das feições, nem preteamento grotesco, o que era comum. O enredo é a jornada da guria inspirada na pergunta sobre qual a diferença entre ser uma menina negra e todas as demais meninas. A estrutura armou pequenas historietas para a filósofa perguntadeira discorrer sobre percepções de nosso cotidiano para colocá-las em xeque. Foi uma forma de propor o trabalho com sentidos culturais, foco da antropologia. E segui acumulando autorias que ampliem o escopo da visão sem perder de vista a origem continental para o imaginário no jogo entre construir identidades e alteridades no dinamismo que os projetos enfrentam.

Revista Crioula: Em outras ocasiões, você já disse que obras literárias comunicam não somente por meio do texto escrito. Como você compreende a dimensão das imagens na literatura para crianças e jovens?

Heloisa Pires Lima: No livro, a ilustração entrega a mensagem antes da escrita. É imediata e central no formato proposto. Minhas pesquisas na perspectiva da antropologia visual treinaram a sensibilidade acerca da independência entre a redação e o desenho, mais a relação entre elas formando uma terceira margem. Levei esse conhecimento para a área editorial. Porém, para além do estético, as figuras negras cravam argumentos culturais na expressão facial, no esquema corporal, nas vestes, no cenário onde são posicionadas, no relacionamento com protagonismos. A Preta, do livro citado, provoca o leitor para o respeito à referência e não para o sentir pena, como era mais usual. A narrativa promove a transformação do olhar sobre a humanidade negra, cuidando para as associações não ficarem sempre restritas a poucas situações, apenas na chave da dor e sofrimentos além da estereotipia rala. Nos acervos, a visualidade realiza metade dessa tarefa.

Por isso, considerando o histórico de inadequações, tento sempre conversar com quem ilustra meus textos. Porém, o gesto é um andar no fio da navalha, pois a visualidade também é uma autoria e criação interpretativa da escrita. É preciso respeitá-la. Mas, algumas vezes, a troca melhoraria o produto. Mas, isto depende da elegância da editora, do profissional estar aberto para ouvir sem se sentir ameaçado. No entanto, há limite. Eu cheguei a vetar ilustrações nunca pelo aspecto estético, e sim pelo debate acerca das representações sociais. A editoria, mesmo diante do desconhecimento de algum assunto, pode intermediar sem deixar de respeitar a criação dos textos. Todavia, imagine o desenho de um baobá, uma planta com aparência peculiar, no desenho uma árvore de senso comum? Outras vezes, apesar de eu ter realizado uma pesquisa de fôlego para uma biografia, a editora não 
considera levando a perder a densidade na imagem do biografado. Mas, acontecem bons encontros. Lendas da África Moderna (2010) é exemplar como um deles. A troca foi realizada no tempo lento, sem a editora apressar.

Revista Crioula: A língua, com seu léxico, grafias, estruturas, entonações, leva consigo uma história. Que história a língua portuguesa do Brasil carrega e como você pensa essa questão na sua escrita?

Heloisa Pires Lima: Em particular, quem trabalha com os léxicos na procedência africana teria que ter à disposição inúmeros estudos de caso espalhados no tempo e cercando localidades. Língua não tem perna, mas anda. Quando eu coordenei o A mbira da beira do rio Zambeze (2009), do musicista e pesquisador Décio Gioielli, as incursões iniciaram no nome do instrumento em torno do qual giraria a narrativa. No ocidente conhecido como "kalimba", mas a pesquisa para o livro foi circunscrevendo a sociedade xona que vive à beira do rio indicado, onde lá é chamado "mbira". Conforme aprofundávamos a relação desse povo com suas mbiras, o que aparentemente parecia similar, não era. Vale destacar que a intensidade do contato com a cultura precisa encontrar a ludicidade para ser recontada, no caso, para crianças brasileiras. A obra resultou uma série de cantigas xona, recolhidas pelo autor na região como a empreendida através do Ministério da Educação e Cultura da Namíbia, um intercâmbio cultural para estudar Mbira Dza Vadzimu com o prof. Emmanuel Karamazondo. Ele explorou arquivos na África do Sul e Zimbábue. As cantigas que entraram para o livro foram mantidas na língua original em $\mathrm{CD}$ ao mesmo tempo que traduzidas pelo músico.

Numa seção final informativa, bolamos a brincadeira "Onde está a mbira", oferecendo registros de Rugendas e Debret. A ideia era ressignificar essas imagens do passado chamando a atenção para certo detalhe nelas. $\mathrm{E}$ assim mostrar que muitos dos instrumentos africanos vieram ou foram refeitos no Brasil, aludindo certa continuidade cultural, potencializando a noção da riqueza cultural em África e no Brasil. Mas aconteceu um episódio de bastidores. Foi quando descobrimos uma anotação de Debret sobre o instrumento. Na descrição a palavra redigida é "ambura". A surpresa foi a grafia particular mais próxima de "mbira" na transcrição de Debret, o que não foi mantido nos diversos tocadores do instrumento em seu relato oficial quando ele o chama de "marimba". Olha que dado fantástico para a reflexão sobre empréstimos lexicais relacionados a alterações fonéticas, fonológicas e morfológicas. A minha atenção é voltada para os sentidos envolvidos, o que exige muita pesquisa, consulta de dicionários das inúmeras línguas africanas expansivos no tempo e toda a produção de 
conhecimento do caso, lá e cá.

Outro projeto que coordenei, Olelê: uma antiga cantiga da África (2015), circunscreve a região em torno do rio Cassai, na República Democrática do Congo. Por meses, eu e Fábio Simões, o autor, estudamos a língua lingala, cartografias da época da cantiga para falar de um costume cultural. No texto para crianças a trabalheira não aparece se tornando, apenas, uma cantiga que vem do coração da África. Uma seção para a criança aprender a falar lingala, entrar em contato, muitas palavras são próximas do português, pois essa colonização passou por lá também. Por outra ordem de questões, aprofundar o saber acerca dos falares africanos no Brasil aqui estava vinculado aos falares do português em África. O diálogo com artistas africanos, também de infinitas possibilidades, afasta traduções culturais pobres, porque eles já conhecem bem mais que eu suas histórias.

Revista Crioula: Seu livro Histórias da Preta (1998) ocupa um lugar de grande importância e destaque. Quais outros autores e autoras de literatura para crianças e jovens enfrentam com seriedade a questão racial?

Heloisa Pires Lima:O mais recente e que me encanta como projeto e alcance conceitual e artístico é Benedito (2019), de Josias Marinho. É um livro de imagem onde ele coloca o protagonista se relacionando com um tambor de Congada. Ao retomar uma afro-mineira-brasilidade para os acervos da infância, ele desarma preconceitos. O premiadíssimo Marcelo d'Salete se tornou o rei das HQs reconhecido mundialmente. O histórico de livros antirracistas tem Kiusam de Oliveira, cujo $O$ mundo no black power de Tayó (2013) mostrou como trazer a noção de luta negra com ludicidade, a construção guerreira, mas afetuosa, para todas as crianças admirarem. Sobretudo, aos leitores e leitoras negras. Ela e Nilma Lino Gomes introduziram a temática penteados afros com maestria. Oswaldo Faustino, o poeta e memorialista e referência da comunidade negra paulistana, tem criado personagens numa produção ainda pequena pelo talento que ele demonstra em ideias e textos que escreve. Outro poeta, Edimilson de Almeida Pereira visou o público infantil. Meire Cazumbá, ela mesma nascida na comunidade de Rio das Rãs, na Bahia, recupera o ambiente do quilombo sem estereotipia em seu Histórias da Cazumbinha (2010). Délcio Teobaldo, que ganhou o Prêmio Barco a Vapor, em 2008, com seu Pivetim, construiu um emaranhado simbólico de estruturas para as andanças do personagem. Esmeralda Ortiz, com o Diário da rua (2003), trata da brincadeira de polícia e ladrão na perspectiva de crianças que vivem na rua. Joel Rufino que chegou a ser indicado ao prêmio Hans Christian por duas vezes, Geni Guimarães que obteve sucesso com o juvenil A cor da ternura (1989), 
Rogério Andrade e suas muitas Áfricas de andanças pelo continente.

Eu estou citando as investidas profissionais na área, esquecendo de muitos. Porém, rememorar a autoria negra passa pela questão do acesso à produção de livros. Nossos acervos foram abastecidos deixando de fora o ponto de vista negro e muitos ângulos para associar o segmento populacional de nossa realidade. Poucos elementos foram oferecidos para o imaginário, o que age sobre o real sendo capaz de promover genocídios naturalizados. Porém, sempre houve, por todas as direções do país, iniciativas locais que mesmo sem amparo e muitas vezes auto-publicações contribuíram para a representatividade local. Livreiros incansáveis em reunir essa produção. E nos nossos dias, novas editoras vêm surgindo descobrindo talentos, equalizando esse acesso e enriquecendo o cenário das publicações antirracistas.

Revista Crioula: O marimbondo do quilombo (2010) compartilha a história de Zumbi e de Palmares; Quilombololando (2016) homenageia os quilombos do Vale do Jequitinhonha. 0 que te motivou a contar essas histórias para crianças?

Heloisa Pires Lima: Eu, visitando escolas, perguntei a um $2^{\circ}$ ano se conheciam Zumbi. Como resposta apareceram tantos zumbis monstros, um mais medonho que o outro. Foi então que me perguntei: cadê o nosso Zumbi? O marimbondo é baseado em Palmares, sendo o narrador um marimbondo só revelado na última frase: E quem tudo te contou? Eu, o marimbondo sentado no título desta história. Além de correr os olhos para ver o inseto na capa, as crianças reviram as páginas para encontrá-lo onde antes não havia sido percebido. Já Quilombololando é uma ciranda que recupera o repertório regional do Jequitinhonha como brincadeira. A ideia surgiu a partir dos desenhos de um artista local. Não deu certo na editora, que chamou Joaquim de Almeida com suas cores para a proposta. O livro é bonito.

Há muitos anos eu visitei uma escola quilombola e só encontrei livros da Xuxa e outros levando uma visão bem colonialista. Desde aí constatei a urgência, em especial a importância do espelho para as novas gerações com histórico quilombola. Além de entrever a infância quilombola eu tenho incluído a autoria. Para o meu juvenil O fio d'água do quilombo (2012), nascido nos quilombos de Santarém, eu convidei duas coautoras. A temática quilombos me desafia também pela própria conotação semântica implicada. A referência foi tratada como lugar de negros fujões. No entanto, quem foge não enfrenta. E a história dos quilombos é a história mais nobre de enfrentamento. Da 
mesma forma, a categoria quilombo quando remetida a lugar de "escravos" coloca em segundo plano o fato do reestabelecimento da vida livre dentro de um poderoso sistema escravista. A associação correta é com a vida livre e não com a escravizada.

Revista Crioula: Dentre as várias abordagens, seus livros são uma oportunidade para conversar com crianças sobre temas complexos como o racismo. Essa é uma possibilidade que você deseja em suas obras?

Heloisa Pires Lima: Lá atrás, eu recebi o convite como autora do Histórias da Preta para uma aula na pós-graduação de matemática. Entre tantos aparentemente esdrúxulos, eu digo que a jornada da Preta dava saltos para fora das páginas. Na época, o público adulto se sentia atraído pelo livro e menos tensionado para discutir algumas das questões que a Preta apresentava. Muitas das historietas tratam ângulos do racismo diretamente, como a definição "negro" no dicionário do Aurélio. Nas obras que se seguiram, a questão está lá, mas oblíqua. O espelho dourado (2003), publicado na sequência, mediava a produção de conhecimento em sala de aula, sobre alguma África. A partir dele, eu participei de projetos ao lado de professores. Em 2003 foi o momento em que a alfabetização eletrônica começava a entrar nas escolas. Acrescentando o conteúdo à desenvoltura tecnológica, coloquei em contato uma escola da Nigéria com uma brasileira. Harmonizando mesma faixa de idade, por um semestre trocaram e-mails, fotos, descreveram a vida daqui e a de lá. Noutro semestre o escritor Meshack Asare, de Gana, também participou do projeto, ele lá e as crianças cá. O envolvimento, de alunos, professores, o meu mesmo, não era burocrático. Havia tanta vitalidade na riqueza do contato intercultural. Falar a respeito do racismo com crianças é importante, mas desmanchá-lo é muito mais. É necessário ampliar temáticas, as correlações, para perceber humanidades negras, o modo de unir o lúdico às questões raciais. Alargar parâmetros construtivos e positivos foi importante. Até para se retomar questões difíceis com uma geração mais fortalecida, justamente, em parâmetros.

Revista Crioula: Muitas vezes, as práticas escolares de leitura literária desconsideram o leitor, deixando pouco ou nenhum espaço para a sua expressão. Gostaria que você falasse um pouco sobre como enxerga essa questão, enquanto educadora e escritora.

Heloisa Pires Lima: Educar é chamar a atenção para um detalhe do mundo e, depois, produzir 
conhecimento sobre ele. Dar respostas estraga o processo de entendimento, seja pela via da razão ou do coração. Rodeada de crianças, eu sei o quanto elas propõem desafios, têm reações inovadoras para o aprendizado nunca de mão única. $\mathrm{O}$ adulto necessita de espaço para elaborar e lidar com as situações do cotidiano escolar. A diferença está nas estratégias construídas a partir das observações de cada aluno e de cada grupo ou projeto pedagógico. E os livros podem ser bons companheiros de estratégias tanto quanto do brincar espontâneo. O livro é um brinquedo e o literário uma vivência refinada. Para o aspecto do formar leitores e leitoras eu tenho acrescentado a pergunta: cabem nele livros racistas? O respiro e a escuta chamam para si a responsabilidade sobre a tônica geracional. E muitas vezes, em nome da leitura literária, há o repasse de lógicas racistas como se a faixa etária infantil e juvenil fosse de acadêmicos maduros com defesas elaboradas para lidar com elas. Por isso, espaços de formação para mediadores de leitura são fundamentais. A fruição é tão necessária quanto a troca de ideias sobre as obras, dispondo num crescente o prazer em conhecê-las. 